\title{
Vitamin D status of pregnant mothers and its effect on anthropometric measures in the offspring: A preliminary study
}

\author{
*K Anusha ${ }^{1}$, U P K Hettiaratchi ${ }^{2}$, G Liyanage ${ }^{3}$, D P S Gunasekera ${ }^{4}$
}

Sri Lanka Journal of Child Health, 2018; 47: 210-214

\begin{abstract}
Introduction: Many studies from the Asian region have shown the existence of vitamin D deficiency among pregnant and breast feeding mothers despite abundant sunlight. Yet, we have little information on this topic in Sri Lanka. There are many skeletal and non-skeletal effects of vitamin D deficiency.
\end{abstract}

Objectives: To investigate vitamin D status of pregnant mothers and its effect on growth parameters of the offspring.

Method: We recruited 91 mothers who did not receive vitamin D supplementation during their pregnancy. 25(OH) D, parathyroid hormone $(\mathrm{PTH})$, alkaline phosphatase, calcium and inorganic phosphorus levels were measured during the third trimester. Weight, length and head circumference (HC) of the babies were measured at birth and at one month of age.

Results: Vitamin D deficiency $(<10 \mathrm{ng} / \mathrm{ml})$ was present in $18.8 \%$ and insufficiency $(10-20 \mathrm{ng} / \mathrm{ml})$ in $47.5 \%$. This study showed no significant correlation between maternal vitamin-D levels and neonatal anthropometry (height, weight and head circumference).

Conclusions: A significant rate of vitamin D deficiency was observed in pregnant mothers. There was no correlation between maternal vitamin-D levels and neonatal anthropometry in this study.

DOI: http://dx.doi.org/10.4038/sljch.v47i3.8540

${ }^{1}$ Research Assistant/ Clinical Nutritionist, ${ }^{2}$ Senior Lecturer, Department of Biochemistry, ${ }^{3}$ Senior Lecturer, Department of Paediatrics, ${ }^{4}$ Professor, Department of Paediatrics, Faculty of Medical Sciences, University of Sri Jayewardenepura, Sri Lanka

*Correspondence: anushakanesh@yahoo.com (Received on 15 August 2017: Accepted after revision on 15 September 2017)

The authors declare that there are no conflicts of interest

Funded by the University of Sri Jayewardenepura.

(Research grant ASP/01/RE/MED/2015/40).

Open Access Article published under the Creative

Commons Attribution CC-BY (cc) (P) License
(Key words: Vitamin D status, pregnant mothers, anthropometry, offspring)

\section{Introduction}

Many studies conducted in other Southeast Asian countries have shown that vitamin D deficiency during pregnancy is common ${ }^{1,2}$. Yet, we do not have any information on vitamin $\mathrm{D}$ status during pregnancy, in Sri Lanka. Few studies conducted locally have shown that deficiency exists in women in reproductive age group and in preschool children $^{3,4}$.

Reasons for vitamin D deficiency in pregnancy could be multifactorial. Limited sun exposure, inadequate dietary intake, lack of supplementation during pregnancy and genetic makeup could be some of the causes ${ }^{5,6,7}$. Effects of vitamin D deficiency are many. Considerable number of studies have shown that there is a link between maternal calcium and vitamin D status and fetal growth $^{1,8}$. However, some studies have failed to demonstrate a relationship between vitamin D and neonatal growth parameters ${ }^{9,10,11}$. Reasons for such mixed results could be variations in study design, ethnicity and laboratory methods used.

\section{Objectives}

To investigate vitamin $\mathrm{D}$ status of pregnant mothers who are not receiving vitamin D supplements and to correlate vitamin D levels to growth parameters of the offspring.

\section{Method}

This study was approved by Ethics Committee of Faculty of Medical Sciences, University of Sri Jayewardenepura. Pregnant mothers in their $3^{\text {rd }}$ trimester were recruited from the obstetric department in Colombo South Teaching Hospital. Convenient sampling technique was employed and all mothers attending the antenatal clinic in their $3^{\text {rd }}$ trimester were assessed for eligibility to participate in the study. Exclusion criteria were mothers already on vitamin D supplements, multiple pregnancy, serious medical problems (nonobstetric) and disability that could be related to bone metabolism.

Written informed consent was taken after explaining the purpose of the study. We collected data on demography, obstetric history, general health and past medical and surgical conditions, 
details of diet, sun exposure, medications and nutritional supplements. Details on diet and sun exposure will be reported separately. Gestation was calculated using mother's last menstrual period and ultrasonography. Fetal growth restriction of the baby was defined as birth weight below the 10th percentile for the gestational age and sex.

Eligible mothers were interviewed and a brief clinical examination performed. Their weights and heights were recorded. Venous blood samples were taken and transported to the biochemistry laboratory at Faculty of Medical Sciences, University of Sri Jayewardenepura. Serum separation was done without delay and stored at $80^{\circ} \mathrm{C}$ until analysis. Follow up included taking anthropometric measurements of the baby at birth and at one month of age. Reminders via telephone calls (maximum of 3 ) and a stipend for transport were provided for parents. Research assistants checked the calibration of weighing scales at least 3 times per week. Length was measured with an infantometer. Non-stretchable plastic tape was used to measure head circumference. We also collected information on baby's feeding, general health and supplementation received.

Analysis of 25-(OH) D was done by VIDAS ${ }^{2} 25$ $\mathrm{OH}$ Vitamin D Total, in serum using the Enzyme Linked Fluorescent Assay (ELFA) ${ }^{12}$. It is very well correlated to the Liquid Chromatography-Mass Spectrometry/Mass Spectrometry reference method with cross reactivity of $100 \%$ with $25 \mathrm{OH}$ Vitamin D3 and 91\% with Vitamin D2. Analysis of calcium, phosphate and alkaline phosphatase was done using the colorimetric method. The DRG (EIA-3645) Intact-PTH ELISA was employed for quantitative determination of intact-PTH in serum $^{13}$.
SPSS version-15 was used for statistical analysis. We applied Spearman correlation to study the influence of $25(\mathrm{OH}) \mathrm{D}$ and parathyroid hormone (PTH) on weight, length, and head circumference at birth and at one month of age. Relationship between neonatal anthropometric measures and maternal biochemical parameters was analysed using Spearman correlation and non-parametric tests (Mann-Whitney test).

\section{Results}

We recruited 91 pregnant mothers in their third trimester. Out of 11 who withdrew, 8 subjects found it either difficult to travel to the study centre or they were planning to move away from the area they were living at the time of recruitment. One baby developed respiratory distress after birth and was transferred out to a neonatal intensive care unit (NICU) for further care. Two mothers did not bring their babies for review. Final analysis included details of 80 respondents. Baseline characteristics of mothers who did not complete the study were compared with the final sample included for analysis. There was no significant difference between the two groups.

Cut off values for $25(\mathrm{OH}) \mathrm{D}$ levels were taken as deficiency $<10 \mathrm{ng} / \mathrm{ml}$, insufficiency $10-20 \mathrm{ng} / \mathrm{ml}$ and sufficiency $>20 \mathrm{ng} / \mathrm{ml}$, according to institute of medicine (IOM) report and the consensus report on nutritional rickets ${ }^{14,15}$. Maternal serum 25(OH) D $<10 \mathrm{ng} / \mathrm{ml}$ was found in $18.8 \%$ of the mothers and $66.3 \%$ mothers had values $<20 \mathrm{ng} / \mathrm{ml}$. 25(OH)D levels, parathyroid hormone (PTH) levels and bone biochemistry of the respondents are shown in Table 1.

Table 1: $25(\mathrm{OH})$ D levels, parathyroid hormone levels and bone biochemistry of the respondents

\begin{tabular}{|l|c|}
\hline \multicolumn{1}{|c|}{ Biochemical parameter } & Mean (SD) \\
\hline $25(\mathrm{OH}) \mathrm{D}(\mathrm{ng} / \mathrm{ml})$ & $18.1(7.6)$ \\
\hline Serum corrected calcium $(\mathrm{mmol} / \mathrm{L})$ & $2.3(0.2)$ \\
\hline Alkaline phosphatase $(\mathrm{IU} / \mathrm{L})$ & $183.6(55.2)$ \\
\hline Parathyroid hormone $(\mathrm{pg} / \mathrm{ml})$ & $26.4(20.9)$ \\
\hline Inorganic phosphorus $(\mathrm{mmol} / \mathrm{L})$ & $1.32(0.22)$ \\
\hline
\end{tabular}

Mean serum PTH was 26.4 (SD: 20.9) PTH cut off was taken as $66.5 \mathrm{pg} / \mathrm{ml}^{13}$. Only $5 \%$ mothers had PTH levels above upper limit of normal. However, maternal serum PTH showed a significant negative correlation with maternal $25(\mathrm{OH}) \mathrm{D}(r=-0.303, p=$ 0.0006).
Further, median level of PTH was significantly higher $(p=0.001)$ in $25(\mathrm{OH}) \mathrm{D}$ deficient group (22.9 $\mathrm{pg} / \mathrm{ml})$ when compared to non-deficient group $(12.17 \mathrm{pg} / \mathrm{ml})$ according to Mann-Whitney test. Relationship of $25(\mathrm{OH}) \mathrm{D}$ and PTH to other biochemical parameters are shown in Table 2.

Table 2: Correlation of parathyroid hormone (PTH) and $25(\mathrm{OH}) \mathrm{D}$ with other biochemical parameters

\begin{tabular}{|l|c|c|c|}
\hline & Calcium & Alkaline phosphatase & Phosphorus \\
\hline PTH & $-0.252(0.024)$ & $0.223(0.048)$ & $-0.423(0.000)$ \\
\hline Vitamin D & $0.110(0.332)$ & $-0.074(0.515)$ & $0.238(0.033)$ \\
\hline
\end{tabular}

Values are for $r$ ( $p$ value) unless otherwise stated 
PTH showed a significant correlation to calcium, alkaline phosphatase and inorganic phosphorus according to Spearman's correlation coefficient test.
Anthropometry of the infants at birth and at one month of age are given in Table 3 .

Table 3: Anthropometry of infants at birth and at one month of age

\begin{tabular}{|l|c|c|}
\hline & At birth: Mean (SD) & At one month: Mean (SD) \\
\hline Weight $(\mathrm{kg})$ & $3.01(0.5)$ & $4.1(0.8)$ \\
\hline Length $(\mathrm{cm})$ & $51.7(6.4)$ & $55.5(4.3)$ \\
\hline Head circumference $(\mathrm{cm})$ & $32.7(4.0)$ & $36.6(1.3)$ \\
\hline
\end{tabular}

Correlation between biochemical parameters (vitamin D, PTH) and growth (weight, length, OFC) was not significant. No confounding effect of gestational age, sex of the infant, maternal height on infant anthropometry was found with 4-way ANOVA.
We grouped maternal vitamin D levels into insufficient/deficient $(<20 \mathrm{ng} / \mathrm{L})$ and sufficient categories. There was no significant effect on growth parameters of the infant even if the mother showed vitamin D insufficiency/deficiency (Table 4).

Table 4: Comparison of birth parameters of infants with maternal 25(OH)D sufficiency and insufficiency /deficiency

\begin{tabular}{|l|c|c|c|c|c|}
\hline & Weight (kg) & Length (cm) & OFC (cm) & $\begin{array}{c}\text { Maternal } \\
\text { height }\end{array}$ & $\begin{array}{c}\text { Gestational } \\
\text { age }\end{array}$ \\
\hline Insufficient/deficient $(\leq 20 \mathrm{ng} / \mathrm{ml})$ & 3.0860 & 51.7547 & 32.5660 & 154.7 & 38.1 \\
\hline Sufficient $(>20 \mathrm{ng} / \mathrm{ml})$ & 2.8804 & 51.5185 & 33.0741 & 153.0 & 38.0 \\
\hline$p$ value & 0.052 & 0.838 & 0.482 & 0.259 & 0.739 \\
\hline
\end{tabular}

\section{Discussion}

Vitamin D status of most age groups in Sri Lanka has not been adequately verified. As far as we know, this is the first study evaluating vitamin D levels in pregnancy. Majority of the mothers in our study had vitamin D insufficiency defined as levels below 20ng/ml. Thus, the likely public health issues that could arise with low vitamin D levels during pregnancy are considerable.

Although we have abundant sunlight throughout the year in Sri Lanka, several other reasons may be contributing to vitamin D deficiency. Change in life style leading to less exposure to sun, low affordability to vitamin D rich food items, high demand for vitamin D during pregnancy and genetic makeup could be some of the reasons for this high rate of deficiency. State sector clinics in Sri Lanka provide oral calcium for pregnant mothers, but no vitamin D supplements. On the other hand patients who can afford to receive care in private sector institutions are given both vitamin $\mathrm{D}$ and calcium supplements.

We examined the relationship of PTH to serum $25(\mathrm{OH})$ D. There was a significant negative correlation between PTH and $25(\mathrm{OH}) \mathrm{D}$. Yet, very few had PTH values above $65 \mathrm{pg} / \mathrm{ml}$ and expected rise in PTH was not seen with maternal vitamin D insufficiency. More information on vitamin D receptor function and genetic composition influencing bone metabolism is needed. Further, re- evaluating vitamin D cut off levels for our population is worthwhile.

Adverse effects of vitamin D are many. However, in contrast to evidence from some studies, we could not demonstrate any effect of maternal 25-(OH) D in the third trimester on anthropometry of the infant ${ }^{1,8}$. According to Morley et al low maternal $25-(\mathrm{OH}) \mathrm{D}$ in late pregnancy is associated with reduced intrauterine long bone growth ${ }^{8}$. Same author has suggested in another report that the relationship between vitamin $\mathrm{D}$ level and birth size may require considering vitamin $\mathrm{D}$ receptor genotype when interpreting ${ }^{16}$. Thus, it is suggested that not only the vitamin D level but other factors like vitamin $\mathrm{D}$ binding protein and vitamin D receptor may be influencing the association between growth of fetus and $25(\mathrm{OH}) \mathrm{D}$. Peng Shui et al has reported that there is an inverted $\mathrm{u}$ shape relationship between vitamin D status and bone growth $^{1}$. It indicates that vitamin D supplementation needs to be titrated carefully, since hyper-vitaminosis D can suppress the bone growth. Findings of few other studies resembled our results; being unable to show a relationship ${ }^{9,10,11}$. It is clear that there is lack of consensus and this conflicting evidence could be due to variations of study designs, timing of vitamin $\mathrm{D}$ testing during pregnancy, cut-off point of vitamin D deficiency, ethnicity and genetic variation of the study population. 
High PTH levels are usually considered as a sign of stress to calcium metabolism. The result of this stress could lead to low fetal growth. Scholl et al has reported that maternal calcium metabolic stress, rather than low calcium or insufficient vitamin D, adversely affects fetal growth ${ }^{17}$. However, present study could not report a relationship between high PTH affecting neonatal anthropometry.

A significant percentage of pregnant women in this cohort had vitamin D deficiency/insufficiency. Since PTH rise was not significant in $25(\mathrm{OH}) \mathrm{D}$ deficient mothers, whether the cut-off value for $25(\mathrm{OH}) \mathrm{D}$ should be adjusted to suit our population of pregnant mothers remains to be elucidated in future studies. We concluded that neither $25(\mathrm{OH})$ D nor PTH levels associated with growth parameters of the offspring. However, possible involvement of other mechanisms at receptor level or vitamin D binding proteins warrants further investigation.

There were several limitations in this study. Since we measured $25(\mathrm{OH})$ D levels only in the $3^{\text {rd }}$ trimester, which does not correspond to vitamin D status in early pregnancy. Since this was a preliminary study and was conducted in a teaching hospital in one district, it is not suitable to generalise these findings to other regions in the country.

\section{Conclusions}

A significant rate of vitamin D deficiency was observed in pregnant mothers. There was no correlation between maternal vitamin-D levels and neonatal anthropometry in this study.

\section{References}

1. Zhu $\mathrm{P}$, Tong $\mathrm{S}, \mathrm{Hu} \mathrm{W}$, Hao J, Tao $\mathrm{R}$, Huang $\mathrm{K}$ et al. Cord blood 25hydroxyvitamin D and fetal growth in China. Anhui Birth Cohort Study. Oct 2005. Scientific Reports.

2. Sachan A, Gupta R, Das V, Agarwal A, Awasthi P, Bhatia V. High prevalence of vitamin D deficiency among pregnant women and their newborns in northern India. American Journal of Clinical Nutrition 2005; 81:1060-4.

PMid: 15883429

3. Rodrigo 1M, Hettiarachchi M, Liyanage C, Lekamwasam S. Low serum vitamin D among community-dwelling healthy women in Sri Lanka. Health 2013; 5:19972003.

https://doi.org/10.4236/health.2013.512270
4. Marasinghe E, Chackrewarthy, Abeysena $\mathrm{K}$, Rajindrajith S. Micronutrient status and its relationship with nutritional status in preschool children in urban Sri Lanka. Asia Pacific Journal of Clinical Nutrition 2015; 24(1):144-51.

PMid: 25740753

5. Kovacs CS. Vitamin D in pregnancy and lactation: maternal, fetal, and neonatal outcomes from human and animal studies. American Journal of Clinical Nutrition 2008; 88(suppl):520S-8S

PMid: 18689394

6. Tsiaras $\mathrm{WG}^{1}$, Weinstock MA. Factors influencing vitamin D status. Acta Derm Venereol. 2011; 91(2):115-24. https://doi.org/10.2340/00015555-0980 PMid: 21384086

7. Kholy MH, Elsedfy H, Fernández-Cancio M, Hamza RT, Amr NH, Ahmed AY et al. Nutritional rickets: vitamin D, calcium, and the genetic make-up. Pediatric Research 2017; 81: 356-63. https://doi.org/10.1038/pr.2016.222 PMid: 27973470

8. Morley R, Carlin J, Pasco JA, War JD. Maternal 25-hydroxyvitamin D and parathyroid hormone concentrations and offspring birth size. The Journal of Clinical Endocrinology \& Metabolism 2005; 91(3): 900-12.

9. Eggemoen $\AA R$, Jenum AK, Mdala I, Knutsen KV, Lagerløv P, Sletner L. Vitamin D levels during pregnancy and associations with birth weight and body composition of the newborn: a longitudinal multiethnic population-based study. British Journal of Nutrition 2017; 117(7): 985-93. https://doi.org/10.1017/S000711451700068 $\mathrm{X}$

PMid: 28468694

10. Brooke OG, Brown IR, Bone CD, Carter ND, Cleeve HJ, Maxwell JD et al. Vitamin D supplements in pregnant Asian women: effects on calcium status and fetal growth. British Medical Journal 1980; 280:751- 4. https://doi.org/10.1136/bmj.280.6220.1054d PMid: 6989438 PMCid: PMC1600591

11. Brunvand L, Quigstad E, Urdal P, Haug E. Vitamin D deficiency and fetal growth. Early Human Development 1996; 45:27-33. 
https://doi.org/10.1016/03783782(95)01719 $-4$

12. VIDAS $25 \mathrm{OH}$ vitamin $\mathrm{D}$ total kit manual. Available from: http://www.biomerieuxdiagnostics.com/vidas-25-oh-vitamin-d$\underline{\text { total }}$

13. PTH Intact (Parathyroid Hormone) from DRG International kit manual. Available from: http://www.biocompare.com/9956Assay-Kit/1092213-PTH-IntactParathyroid-Hormone/

14. Ross AC, Manson, JE, Abrams SA, Aloia JF, Brannon PM, Clinton SK et al. The 2011 Report on dietary reference intakes for calcium and vitamin $\mathrm{D}$ from the Institute of Medicine: What clinicians need to know. Journal of Clinical Endocrinology and Metabolism 2011; 96:53-8.

https://doi.org/10.1210/jc.2010-2704

PMid: 21118827 PMCid: PMC3046611

15. Munns CF, Shaw N, Kiely M, Specker BL, Thacher TD, Ozono $\mathrm{K}$ et al. Global consensus recommendations on prevention and management of nutritional rickets. Journal of Clinical Endocrinology and Metabolism 2016; 101:394-415.

https://doi.org/10.1210/jc.2015-2175

PMid: 26745253 PMCid: PMC4880117

16. Morley R, Carlin JB, Pasco JA, Wark JD, Ponsonby AL. Maternal 25hydroxyvitamin D concentration and offspring birth size: effect modification by infant VDR genotype European Journal of Clinical Nutrition 2009; 63: 802-4.

https://doi.org/10.1038/ejen.2008.55

PMid: 19018272

17. Scholl TO, Chen X, Stein TP. Maternal calcium metabolic stress and fetal growth. The American Journal of Clinical Nutrition 2014; 99(4):918-25.

https://doi.org/10.3945/ajen.113.076034 PMid: 24500145 PMCid: PMC3953884 